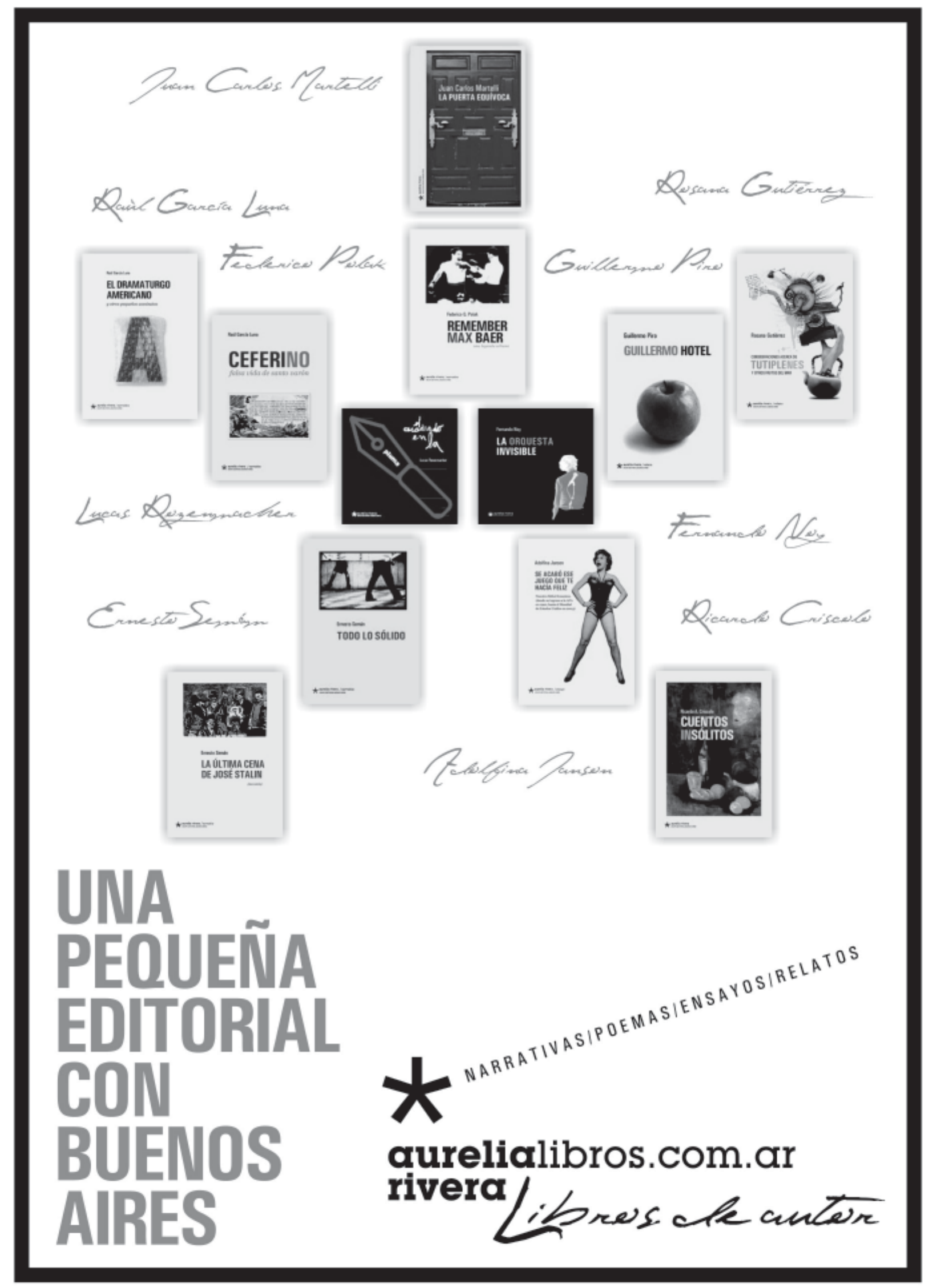




\section{Pasts and futures of economic sociology}

\section{Resumen}

La sociología económica se ha desplazado a lo largo de las últimas décadas desde una fuerte simbiosis con las corrientes dominantes de la economía hacia la construcción de explicaciones alternativas de las actividades económicas. Este desplazamiento ha acercado progresivamente a los sociólogos económicos tanto a producciones innovadoras al interior de la ciencia económica, como a nuevos esfuerzos analíticos por fuera. La suma de estas tendencias ha creado una interpretación claramente más social del dinero y de los mercados.

Sociología económica; ciencia económica; dinero; relaciones sociales.

\section{Abstract}

Over the past few decades, economic sociology has moved from tight symbiosis with mainstream economics toward the construction of alternative explanations for economic activities. That move has allied economic sociologists increasingly with both innovative work inside economics and new analytic enterprises outside. Cumulatively, these developments have created a much more social interpretation of money and markets.

Economic sociology; economics; money; social relations 


\section{Pasados y futuros de la sociología económica*}

VIVIANA ZELIZER**

La sociología económica ha atravesado cambios notables en los últimos 25 años. De ser a la vez crítica y complemento de la economía neoclásica, se ha constituido en un campo rico y autónomo, al punto de comenzar a generar e incorporar alternativas de peso a la economía neoclásica. Estos cambios han influenciado profundamente mi propia actitud hacia la sociología económica y mi relación con ella.

En verdad, algo curioso ocurrió en mi recorrido por este campo. Durante toda mi carrera trabajé sobre diferentes procesos económicos, en libros acerca de cómo los seguros de vida fueron aceptados socialmente, la valoración monetaria de la niñez, las prácticas monetarias interpersonales, y más recientemente acerca de la economía de las relaciones sociales íntimas, así como breves incursiones en tópicos eminentemente económicos como el consumo y el trabajo infantil. Por años, nadie, ni siquiera yo misma, consideró mi trabajo como sociología económica.

En cierto modo, esto era correcto. La sociología económica que se estaba desarrollando hace unos 20 o 25 años se aferraba de cerca a las formas dominantes de la ciencia económica, sea extendiendo sus premisas principales hacia temas más claramente sociológicos, sea identificando los contextos sociales que constreñían la actividad económica -todavía se concebía el comportamiento de esta última de acuerdo con los preceptos económicos neoclásicos. Enfocada casi exclusivamente en temas favoritos de los economistas como las firmas y los mercados, se concentraba en lo que podemos llamar las explicaciones de la extensión y del contexto.

Los teóricos de la extensión aplicaban modelos económicos relativamente estándar a procesos aparentemente no económicos, como
* Traducción: Pablo Palomino. Edición: Daniel Fridman. Traducido de: "Pasts and Futures of Economic Sociology", en Nicole Woolsey Biggart (ed.), número especial "Coming and Going in Economic Sociology.” American Behavioral Scientist, 50 (Abril 2007): 1056-69.

DOI:10.1177/0002764207299353.

Nota de la autora: unos pocos pasajes fueron adaptados de Zelizer (2005a).

* Departamento de Sociología, Princeton University. 
las congregaciones religiosas, el comportamiento doméstico o los equipos deportivos profesionales. Los analistas contextuales, a su vez, se orientaban hacia fenómenos típicamente económicos -corporaciones, mercados de trabajo, de mercancías- mostrando cómo la organización social, como contexto, configuraba las opciones de los actores económicos. Hablaban del "arraigo" (embeddedness) de los fenómenos económicos en procesos sociales, a menudo poniendo atención a las redes interpersonales. Esta aproximación contextual contenía el presupuesto implícito de que los economistas habían acertado con ciertos fenómenos como el ahorro o la formación de precios. Pero ¿qué faltaba, según los sociólogos económicos? Los economistas, sostenían los teóricos del contexto, habían descuidado el contexto social y cultural, como por ejemplo las conexiones previas entre potenciales socios económicos.

En estos últimos diez o quince años, me ha sorprendido a mí y a otras personas el hecho de haberme convertido en un miembro establecido del campo de la sociología económica. ¿Qué sucedió? Parte de la respuesta reside en que aprendí más acerca de la variedad de los trabajos actuales en sociología económica y me involucré más en este diálogo vibrante. Fueron tres los cambios decisivos en mi relación con este campo:

1. Para mi sorpresa, los organizadores intelectuales del campo, como Richard Swedberg, Harrison White y Neil Smelser, comenzaron a ver mi trabajo como ejemplo de una nueva corriente dentro del campo.

2. Me encontré a mi misma enseñando sociología económica a un círculo creciente de estudiantes de grado y posgrado.

3. Los dos cambios mencionados me obligaron a confrontar premisas fundamentales de la sociología económica básica de un modo más directo que cuando me veía a mí misma como una estudiante de la historia y la cultura norteamericanas.

En lugar de concentrarse únicamente en empresas y mercados, me pareció que todas las formas de producción, consumo, distribución y transferencias de activos merecían la atención de los sociólogos económicos, incluyéndome a mí.

Este artículo, por lo tanto, es necesariamente una mezcla de autobiografía intelectual y repaso crítico de los cambios pasados, presentes y futuros de un campo que se mueve rápidamente. Comenzaré con un resumen de los desplazamientos de largo plazo en el estudio de los procesos económicos. Luego realizaré una aproximación a las orientaciones principales y más recientes dentro de la sociología 
económica y discutiré en qué medida ellas cuestionan presupuestos previamente dominantes acerca de las intersecciones entre la vida económica y las relaciones interpersonales. Ilustraré estos tópicos a través de análisis recientes, entre los que se incluye el mío, acerca del dinero. El artículo concluye con una rápida mirada sobre otras tendencias dentro del campo.

\section{Reconsiderando los procesos económicos}

La sociología económica no está sola en su desafío a la comprensión establecida de los procesos económicos. Los grandes cambios ocurridos en este campo fueron simultáneos a otros similares en otras áreas. Tres de ellos merecen especial atención. En primer lugar, dentro de la economía misma. Corrientes como la economía del comportamiento, economía feminista, economía organizacional, economía institucional, dinámicas domésticas, y más recientemente la neuroeconomía, propusieron sus propias críticas a los modelos neoclásicos.

Todas estas nuevas formas de análisis económico comenzaron a crear explicaciones alternativas sobre los procesos económicos, incluyendo el abanico de relaciones interpersonales sobre el cual me he concentrado por muchos años. Algo tan simple como la introducción de la teoría de los juegos en los modelos de negociación doméstica, por ejemplo, sustituyó a los antiguos modelos limitados a las preferencias individuales por una serie de interacciones entre jugadores.

En segundo lugar, por fuera del campo de la economía, críticos del derecho y la economía, teóricos de las organizaciones, estudiosos de la desigualdad y feministas críticos contribuyeron a nuestro pensamiento acerca de cómo los procesos económicos y sociales funcionan realmente. También ellos insistieron en temas como el poder, la negociación y las transacciones interpersonales.

Tercero, en la frontera entre la economía y la sociología surgieron varias disciplinas nuevas, híbridas, proponiendo sus propias versiones de los procesos económicos. Entre ellas se cuentan la socioeconomía, la economía comunitaria, la économie solidaire et sociale francesa y los análisis del sistema mundial.

Al mismo tiempo, los sociólogos económicos no solamente incrementaron su número y su confianza, sino que se movieron desde las perspectivas de la extensión y el contexto hacia la formulación 
3 Véase por ejemplo L'argent en famille, 2005; Boltanski y Chiapello, 1999; Caillé, 1994; Convert y Heilbron, 2004, Cusin y Benamouzing, 2004; De La Pradelle, 1996; Gislain y Steiner, 1995; Guérin, 2003; Hassoun, 2005; SaintJean y Steiner, 2005; Sciardet, 2003; Servet, 1999; Servet y Guérin, 2002; Steiner 1999, 2003; Weber, Gojard y Gramain, 2003; Weber, 2005; Wacquant, 2002. de descripciones y explicaciones de la actividad económica realmente alternativas y basadas en lo social (un estimulante y notorio cambio ocurrió en el mismo sentido dentro de las ciencias sociales francesas). ${ }^{3}$ Este análisis alternativo intentaba identificar procesos sociales y relaciones sociales en el corazón mismo de la actividad económica, incluyendo el hasta entonces sagrado e inexplorado territorio de los mercados. Muchos de estos analistas se apoyaban en la afirmación de Harrison White de que los mercados son creaciones profundamente sociales y no arenas autónomas simplemente afectadas por procesos sociales.

Más aún, durante sus últimos años, Pierre Bourdieu se movía en la misma dirección, y en la edición del año 2000 de su libro Estructuras sociales de la economía sostenía:

Las estrategias que apuntan a "corregir" las insuficiencias o lagunas de un paradigma sin que jamás se lo cuestione verdaderamente (...) hacen pensar en las laboriosas construcciones por medio de las cuales Tycho Brahe se esforzaba por salvar el modelo geocéntrico de Ptolomeo contra la revolución copernicana (Bourdieu, 2001: 26, nota 1).

En general, los sociólogos en busca de una sociología económica alternativa criticaron la idea de "arraigo" (embeddedness), que implicaba que procesos sociales proporcionaban el caparazón a la economía, pero que el contenido de ese caparazón eran los sistemas de intercambio racionales analizados por la ciencia económica. Al igual que los economistas institucionales, que atónitos ante el fracaso de los mercados en transformar por sí solos las economías de las países post-socialistas comenzaron a pensar las actividades económicas como procesos sociales, los sociólogos económicos se aventuraron en el corazón de firmas, mercados, organizaciones e instituciones financieras.

A través de estos cambios, descubrí que mi foco en los aspectos interpersonales significativos de la actividad económica ya no se hallaba en la periferia de lo que sucedía en el campo. Ahora, desde adentro, puedo ver más claramente que este proceso de expansión continúa. Una señal de esto lo proporciona el índice de la segunda edición del Manual de Sociología Económica de Neil Smelser y Richard Swedberg (2005): pueden verse allí nuevo institucionalismo, emociones, economía del comportamiento, derecho, temas todos ausentes en el índice de la primera edición apenas once años antes.

Hay más cambios dentro y alrededor de la sociología económica. Los nuevos temas y aproximaciones incluyen: 
- Mercados múltiples: una expansión desde un enfoque dirigido exclusivamente a la producción, hacia el análisis de otros mercados, especialmente financieros, de consumo, de cuidado personal y lo que se denomina en sentido amplio economía informal.

- Cultura de las empresas: los sociólogos económicos acabaron por deshacerse de la armadura estructural y están estudiando cómo el contenido significativo de los lazos sociales configura las transacciones y los alineamientos dentro de las empresas.

- La producción y reproducción de la desigualdad, especialmente de género: se están cuestionando progresivamente los modelos de adquisición de status que explican la desigualdad como resultado de la confluencia de atributos individuales con una selección de mercado sesgada.

- Los hogares como sitios de intensa actividad económica: en este punto, junto con sus aliados en economía y antropología, los sociólogos económicos no solo identifican producción, consumo, distribución y transferencias de activos extensivas y trascendentes, sino que también encuentran patrones de interacción que no pueden ser representados fácilmente como mercados al contado y de corto plazo.

Mi trabajo reciente muestra la influencia de todas esas innovaciones, especialmente de los análisis de mercados múltiples y hogares. Mi libro de 2005, The Purchase of Intimacy (La compra de la intimidad), por ejemplo, se detiene largamente en cómo, en los Estados Unidos, tanto las prácticas cotidianas como las leyes regulan la intersección de las relaciones interpersonales íntimas con la actividad económica (Zelizer, 2005b). En la pareja, el hogar y la provisión de cuidado personal, las personas se preocupan por hacer coincidir adecuadamente relaciones personales y transacciones económicas. Mostrar el funcionamiento de estos procesos me condujo inevitablemente a criticar interpretaciones ampliamente difundidas, pero erróneas, acerca de las interacciones entre relaciones personales y actividad económica (Zelizer, 2005a)

Más importante, desde mi perspectiva, es el ataque a presupuestos compartidos por economistas y sociólogos, lo que yo denomino las historias gemelas de las esferas separadas y los mundos hostiles. Las esferas separadas se basan en el supuesto de que la actividad económica racional y las relaciones personales constituyen arenas diferentes, una de cálculo y eficiencia, la otra de sentimientos y solidaridad. En el mismo sentido, la doctrina de los mundos hostiles sostiene que el contacto entre ambas esferas resulta en contaminación y desorden: la racionalidad económica corrompe la intimidad, y las relaciones íntimas obstaculizan la eficiencia. 
¿Por qué es importante desafiar esta falsa separación? Porque ella perpetúa divisiones inconducentes entre actividades mercantiles trascendentes, supuestamente "reales", y economías periféricas, triviales. Más específicamente, la dicotomía entre fenómenos económicos serios, como firmas, corporaciones o mercados financieros, por un lado, y economías supuestamente intrascendentes y sentimentales como hogares, micro-créditos, monedas comunitarias locales, asociaciones de ahorro y crédito rotativos de inmigrantes (ros$c a$ ), empeños, regalos o remesas de dinero por el otro. La economía real, en esta mitología, consiste solamente de transacciones mediadas por el mercado, así como el dinero "real" consiste de una única, homogénea y fungible moneda de curso legal.

¿Cuál es el problema de esta visión? Entre otras deficiencias, ignora que, colectivamente, tales transacciones supuestamente menores no son triviales. Tienen en verdad grandes consecuencias macroeconómicas, por ejemplo al generar vastos flujos de remesas de países ricos a países pobres, y al transmitir riqueza de una generación a la siguiente. Como lo ilustra la transmisión intergeneracional de la riqueza, las transacciones íntimas también crean o sostienen desigualdades a gran escala de clase, raza, etnicidad e incluso género. Más en general, la doctrina de las esferas separadas y los mundos hostiles perpetúa la creencia "contextual” de que las actividades económicas obedecen a sus propias leyes, siendo las relaciones sociales apenas un factor externo que las constriñe.

Disconformes con semejante dualismo, y deseosos de proponer explicaciones unificadas de la vida social, los oponentes de la doctrina de los mundos hostiles han enfrentado, entonces como ahora, argumentos reduccionistas de tipo "nada más que": el mundo aparentemente separado de las relaciones personales, argumentan, es nada más que un caso especial de algún principio general. Los defensores del "nada más que" se dividen entre tres principios: nada más que racionalidad económica, nada más que cultura, y nada más que política. Así, para los reduccionistas económicos las relaciones personales de cuidado, amistad, sexualidad o familiares son apenas casos especiales de elección individual orientada por la búsqueda de ventajas en condiciones de restricción -en pocas palabras, de racionalidad económica. Para los reduccionistas culturales, tales fenómenos son nada más que expresiones de creencias particulares. Otros insisten en las bases políticas, coercitivas y de explotación de tales fenómenos. 
Incluso los sociólogos económicos que evitan estos reduccionismos continúan adoptando, lamentablemente, una variación atenuada de la doctrina de las esferas separadas y los mundos hostiles, por ejemplo distinguiendo entre transacciones más mercantiles o menos mercantiles, en lugar de reconocer que todo mercado depende de relaciones interpersonales con sentido continuamente negociadas. No obstante, la sociología económica en general se está alejando de razonamientos basados en la extensión, el contexto y la doctrina de las esferas separadas y los mundos hostiles, moviéndose hacia una concepción plenamente social de la actividad económica.

\section{El caso del dinero}

Estos cambios pueden ser apreciados claramente en el estudio sociológico del dinero. Marx, Weber, Simmel, Simiand y Mauss propusieron influyentes teorías acerca del dinero. Sin embargo, durante buena parte del siglo veinte el estudio del dinero se convirtió en monopolio de los economistas, mientras otros cientistas sociales consideraron el dinero como una especie de intrusión, a menudo peligrosa, en la vida social (véase, por ejemplo, Habermas, 1989). La visión económica dominante absolutizó una concepción mercantil del dinero como operando con leyes autónomas en su propia esfera moralmente neutral, independientemente de las relaciones sociales. Incluso el análisis de Talcott Parsons (1967: 358) del dinero como lenguaje simbólico confinó el simbolismo del dinero dentro del dominio económico. Todavía en 1979 Randall Collins se quejaba de que los sociólogos ignoraban el dinero "como si no fuese suficientemente sociológico" (p. 190).

Desde la década de 1980, sin embargo, investigadores norteamericanos, británicos y europeos han reiniciado la interpretación social del dinero, proponiendo una serie de preguntas que reflejan aquellas planteadas acerca de los procesos económicos en general. ¿Es el dinero realmente un fenómeno abstracto con leyes autónomas? ¿La vida social provee apenas el contexto para las transacciones monetarias? ¿De qué modo ese contexto constriñe al dinero? ¿Cuán vulnerables son las relaciones sociales frente al supuesto impacto corruptor del dinero? ¿O es que acaso el dinero mismo está constituido por lazos sociales y es por lo tanto un proceso y un producto social? ¿Hay un solo dinero, o hay múltiples dineros? 
4 Véase Aglietta y Orléan, 2002; Akin y Robbins, 1999; Baker, 1987; Blanc, 2000; Bloch, 1994; Carruthers y Espeland, 1998; Carruthers, 2005; Cohen, 2003; Dodd, 1994, 2005; Gilbert 2005; Guyer, 1995; Ingham, 2004; Helleiner, 2003; Fishman y Messina, 2006; Keister, 2002; Leyson y Thrift, 1997; Mizruchi y Brewster Stearns, 1994; Pahl, 1989 ; Parry and Bloch, 1989; Raineau, 2004; Singh, 1995; Woodruff, 1999.
Muchos investigadores han contribuido recientemente a este debate. ${ }^{4}$ Significativamente, mientras la primera edición del Manual de Sociología Económica de Smelser y Swedberg incluía un solo ensayo sobre "Dinero, bancos y mercados financieros", la edición de 2005 divide el tema en dos: bancos y mercados financieros en un capítulo, dinero y crédito en otro.

Estos desarrollos dieron forma a mi propia obra. Mi libro de 1994 The Social Meaning of Money (El significado social del dinero) cuestionaba las teorías clásicas que trataban el dinero exclusivamente como un medio impersonal y neutral de intercambio económico apropiado para un mundo contemporáneo orientado por mercados racionales. También desafiaba la más ominosa predicción de que el dinero necesariamente afectaba los lazos sociales con sentido, reduciendo las conexiones interpersonales al cálculo instrumental. Para ello, el libro seguía los cambios en las prácticas sociales en los Estados Unidos que acompañaron la expansión de las transacciones monetarias.

Enfocado a grandes rasgos en el período 1870-1930, el libro explora tales procesos en una variedad de ámbitos: los hogares, la economía de los regalos, y la asistencia social. El análisis muestra que, en efecto, la monetización planteó a los norteamericanos nuevos desafíos, pero también prueba que en lugar de darle la espalda, o de dejar marchitar las relaciones sociales en la persecución indiscriminada de dinero, los norteamericanos lo incorporaron en la construcción de nuevos lazos sociales, y al hacerlo, transformaron su significado. Más específicamente, a medida que el dinero se incorporaba a los hogares, a los regalos y a las donaciones caritativas, tanto individuos como organizaciones inventaron un gran abanico de divisas, desde asignaciones para gastos hogareños y dinero para gastos ocasionales hasta regalos en dinero, vales de regalo, remesas, propinas, pensiones para las madres y vales de comida.

¿Cómo aplica la gente en la práctica las múltiples distinciones descritas en el libro? Hay un patrón recurrente en todos los materiales trabajados en el libro. En cada caso la gente utiliza una serie de prácticas que podemos llamar "marcado" (earmarking): tratamientos del dinero que señalan la naturaleza de la relación entre las partes de una clase particular de transacción. 
Las técnicas del "marcado" incluyen tres variedades principales:

1- El establecimiento de prácticas sociales que ordenan en categorías distintas medios que de otro modo serían idénticos. Dependiendo de cómo se usa, cuándo y fundamentalmente para qué tipo de relación social, un mismo medio, físicamente indistinguible (por ejemplo el dólar o el euro) puede servir como salario, pago extra, propina, regalo, asignación, caridad o remesa. Cada una de estas categorías remite a una serie de rutinas que representan su carácter particular.

2- La creación de medios segmentados en forma de prendas, cupones, títulos, letras, vales de comida, affinity cards*, monedas locales, órdenes de dinero, vales, certificados de regalos. Se trata de medios apropiados para relaciones y transferencias específicas, en muchos casos sin valor en el resto de la economía.

3- La transformación de ciertos objetos en medios monetarios, como cigarrillos, estampillas, pasajes de subterráneo, fichas de póker o figuritas de béisbol.

En este punto dejé el problema en 1994. Aunque recibió respetuosas reseñas, el libro tuvo un impacto menor al que yo esperaba en discusiones más generales sobre procesos monetarios. Sucedió así en parte porque el libro se concentraba en relaciones sociales de pequeña escala y evitaba las polémicas teóricas, con la excepción de las objeciones a las diferentes versiones de la doctrina de la "corrupción monetaria”.

Pero hay una razón fundamental por la cual el libro demoró tanto en producir algún impacto. En su prefacio a la edición francesa de The Social Meaning of Money, Jérôme Bourdieu y Johan Heilbron notaban con astucia que una lectura superficial del libro

corre el riesgo de reforzar la propensión a pensar el análisis sociológico, especialmente en sus versiones culturalistas, como desplazando los fenómenos económicos hacia una segunda dimensión, y concentrándose en fenómenos marginales, proporcionando exóticos aspectos laterales que no tocan los fundamentos de la economía real (Bourdieu y Heilbron, 2005: 14)

Heilbron y Bourdieu están en lo cierto. Más de lo que me daba cuenta al escribir el libro, es fácil para lectores descuidados u hostiles desdeñar el libro como irrelevante por dos razones: que se centra en fenómenos monetarios marginales, no en el dinero "real", y que plantea una explicación esencialmente culturalista, rica en detalles pero no en sustancia.

Puede entenderse el porqué de esta impresión: el libro se concentra en procesos de pequeña escala más que en transformaciones macro-
* (NdT) Affinity Card: tarjeta de crédito que incluye el nombre de una organización que recibe parte del dinero gastado mediante la tarjeta. 
monetarias. Estudia familias, regalos y la economía de la ayuda social, y explora significados monetarios. Dada la propensión de larga data a dividir el mundo económico entre los mercados "reales", serios, de las corporaciones y las finanzas que manejan dinero "real", por un lado, y las economías marginales, supuestamente menores, con sus dineros "cuasi” imperfectos, por el otro, el libro no parece orientarse hacia los espacios económicos decisivos. Si uno cree que la economía real consiste solo en transacciones mediadas por el mercado y que el verdadero negocio del dinero tiene lugar solo dentro de las corporaciones y las finanzas, es fácil considerar los materiales del libro como irrelevantes.

Finalmente, por razones comprensibles, orienté el libro en contra de las visiones corrientes acerca de la mercantilización, del dinero como una fuerza racionalizadora que transforma las relaciones sociales donde sea que vaya. Al intentar mostrar las deficiencias de estos argumentos no subrayé lo suficiente el elemento distintivo de la alternativa que yo proponía. Como resultado, permití que algunos lectores leyesen el principal mensaje del libro así: "el dinero es más cultural que lo que los pensadores tradicionales creían”.

Sin embargo, como lo señalan Bourdieu y Heilbron (2005), tal conclusión es equivocada, por diversas razones:

En primer lugar, el argumento central del libro no es que el dinero es cultural: su contribución más original consiste en conectar las prácticas monetarias con las relaciones sociales, y esto es algo que simplemente no está en el horizonte de la mayoría de los análisis del dinero en las ciencias sociales.

En segundo lugar, y más específicamente, el libro argumenta que las personas diferencian habitualmente formas de transferencias monetarias en correspondencia con sus definiciones del tipo de relaciones que existen entre ellas. Así, adoptan símbolos, rituales, prácticas, sistemas de contabilidad y formas físicamente distinguibles de dinero para remarcar relaciones sociales particulares.

Tercero, las personas se preocupan por mantener esas distinciones: se fijan en diferenciar cuidadosamente los distintos dineros, pues los sistemas de pago son poderosas herramientas para distinguir cada lazo social particular, cada uno de los cuales posee una cualidad propia y exige por lo tanto diferentes formas y rituales de pago. 
Estas relaciones, en mi enfoque, no son las delgadas y chatas relaciones del análisis de redes, sino las ricas relaciones de la etnografía. La etnografía revela mucho de la negociación y la producción real del significado cultural. Este no es un rasgo trivial del dinero. Como dicen Bourdieu y Heilbron, así es como el dinero funciona.

El trabajo relacional y la sanción de relaciones a través del "marcado" son aspectos generales y centrales del dinero. Desde este punto de vista, la cultura no es una entidad abstracta. Las personas crean cultura relacionalmente. El marcado del dinero realza precisamente este punto: el marcado es una práctica relacional. La gente no solamente adopta categorías de la cultura circundante, sino que negocia su vida social, marcando dinero para diferentes series de relaciones.

Hoy plantearía los temas del libro de un modo más polémico. Por ejemplo, un tema obvio que di por sentado y que no enfaticé lo suficiente: los fenómenos monetarios consisten en, y dependen de, prácticas sociales. No podemos tratar el dinero simplemente como el volumen y el flujo de transacciones entre sistemas contables, ni a los medios de tales sistemas como billetes de banco, monedas y créditos. Al tratar el consumo, distribución y transferencia de valores como procesos mediados por el mercado, los analistas se abstraen de las relaciones sociales concretas y las prácticas que constituyen y conducen el consumo, la distribución y la transferencia de valores.

\section{Controversias y convergencias}

Varios años después de su publicación, el foco del libro sobre los lazos y prácticas personales me enfrentó con el curso seguido por otros teóricos. Críticos como Ben Fine y Costas Lapavitsas (2000) y Geoffrey Ingham (2001) insistieron en que el proceso del dinero es generalizador y se sostiene en el poder (véase también Lapavitsas, 2005). Incluso plantearon dudas acerca de que las transacciones que yo había analizado fuesen realmente monetarias.

Por ejemplo, Fine y Lapavitsas (2000) consideraron inapropiado mi énfasis en la heterogeneidad, en particular mi aparente indiferencia por la "influencia homogeneizadora" del dinero (p. 22). Si bien concedían que "es la naturaleza dual del dinero lo que debe siempre ser enfatizado -el dinero, universal y homogéneo, crea el ámbito para expresar relaciones que son social y culturalmente específicas" (idem), las variaciones sociales del dinero, dentro del esquema de 
Fine y Lapavitsas, poco pueden contra sus tendencia a universalizar. "Los rasgos y significados más amplios de las relaciones sociales expresados a través del dinero", sostienen los autores, "se hallan contenidos dentro de la ausencia de atributos distintivos propia de la intercambiabilidad universal” (p. 15). Así, Fines y Lapavitsas insisten tanto en el dinero universal como en la prioridad causal del carácter intercambiable en última instancia del dinero. "Hay un único dinero", afirman, "aun cuando asuma formas diferentes" (p. 29).

Aunque ciertamente conscientes de las dimensiones sociales del dinero, estos críticos se aferran a un enfoque contextual más seguro, que admite la importancia de los constreñimientos sociales del dinero, pero ignora su base relacional. Como resultado, esta visión perpetúa el modelo de las esferas separadas de la vida social y la económica. "El” dinero es lo real; otros dineros, según este modelo, son "cuasi" aproximaciones.

En el debate actual, los sociólogos económicos están realizando grandes esfuerzos por ir más allá, tanto de las críticas del análisis económico como de las interpretaciones contextuales, estudiando por el contrario los procesos sociales reales que constituyen el dinero. Como ha señalado recientemente Bruce Carruthers (2005), esta tendencia ha llegado lejos tanto en el análisis del dinero como de su hermano, el crédito. En este proceso, los estudios actuales están reemplazando la visión clásica del dinero como un medio de intercambio económico simple, homogéneo y líquido, por un continuo que incluye una amplia variedad de medios monetarios.

Consideremos el perspicaz registro realizado por Nigel Dodd (2005) de la pluralidad del dinero. Dodd desafía la obsoleta dicotomía entre "dinero real" y lo que él llama los "dineros débiles" y otros identifican a menudo como "cuasi-monedas". Al introducir la variación del dinero, Dodd propone una admirable agenda de investigación: explicar las diferencias entre las distintas clases de moneda, así como identificar las "diferentes trayectorias causales involucradas en la emergencia de nuevas formas de dinero".

El análisis que realiza Dodd de la variación en las formas de dinero ayuda a formular mejores respuestas a lo que él identifica como una significativa paradoja contemporánea: el simultáneo incremento en la homogeneización de la moneda emitida por los estados y la diversificación de dineros. Más específicamente, este autor utiliza sus herramientas analíticas para identificar lo que él ve como la natura- 
leza "híbrida" del euro. Dodd presenta acertadamente el euro como una llamativa instancia de un proceso recurrente por el cual la homogeneización de la moneda estimula la diversificación del dinero -es decir, diversificación a través de la multiplicación tanto de los medios de circulación no monetarios como de las unidades de cuenta. La aproximación de Dodd comparte así la saludable tendencia de la sociología económica, por la cual los estudiosos se liberan crecientemente de la vieja obsesión de criticar o contextualizar los análisis económicos convencionales.

Sin embargo, Dodd no logra reconocer la incorporación de las relaciones sociales en las transacciones monetarias, y de las transacciones monetarias en las relaciones sociales. Tal reticencia a integrar los elementos sociales del dinero no carece de importancia, pues conduce a Dodd a omitir en su análisis dos elementos cruciales, parcialmente independientes: la diferenciación relacional del dinero y las prácticas monetarias. Las personas habitualmente hacen converger las formas de transferencia monetaria con el tipo de relación que surge de las partes. En cuanto a las prácticas, dependen de símbolos, rituales, sistemas de contabilidad y medios monetarios variados para marcar lazos sociales distintivos.

Qué medios o unidades de cuenta la gente adopta, cuándo y cómo, depende del tipo de relación social involucrada. Padre-hijo, sacerdote-fiel, trabajador social-receptor de ayuda, legislador-votante, parejas cortejándose, todas estas relaciones incluyen a veces transacciones monetarias; pero cada una requiere una combinación diferente de medios y unidades de cuenta. Al calcular quién debe a quién cuáles favores, servicios, tributos y regalos, en los dos extremos de la cadena migratoria, los participantes de las complejas relaciones de un sistema de remesas utilizan a menudo las monedas de los países de emisión y recepción, pero habitualmente crean sus propias unidades híbridas de contabilidad.

Debemos pues llevar el análisis de Dodd un paso más allá. Todos los dineros son, efectivamente, duales; sirven tanto en circuitos locales como generales. Ciertamente esta dualidad es válida para todas las transacciones económicas. Vistas desde arriba, las transacciones económicas se conectan con significados simbólicos e instituciones nacionales más amplios. Vistas desde abajo, sin embargo, las transacciones económicas son altamente diferenciadas, personalizadas y locales, significativas en relaciones particulares. No hay contra- 
dicción pues entre uniformidad y diversidad; son simplemente dos aspectos de la misma transacción. Así como la gente habla inglés de una manera gramaticalmente reconocible al mismo tiempo que colocan contenido individual y personal en sus conversaciones, los actores económicos adoptan modos que universalizan y marcas que particularizan.

Algunos análisis recientes han arribado al mismo punto a través de un camino algo diferente, diciendo que el dinero depende de los sistemas de contabilidad. Estoy de acuerdo, pero con una precisión: los sistemas de contabilidad no son meros mecanismos diseñados en bancos o estados. La gente crea y negocia sus propios sistemas de contabilidad en una escala más pequeña. La gente incorpora y configura las prácticas sociales.

Los analistas tradicionales también se equivocan al confinar a los hogares y a otras economías no mercantiles y sus mundos monetarios a la periferia de la economía real. Se equivocan porque los hogares, grupos de parentesco, redes de amistad, vecindades y organizaciones supuestamente no-económicas como iglesias y asociaciones voluntarias juegan roles significativos en una amplia gama de actividades económicas. Tómese el ejemplo obvio de los sistemas de remesas de migrantes. Estos sistemas se extienden ampliamente en las economías nacionales de países como Turquía y México, pero, para desesperación de muchos economistas especializados en desarrollo, funcionan principalmente a través de lazos de parentesco, amistad y vecindad más que de bancos y otras instituciones económicas formales.

¿Por qué decidí analizar familias, ayuda social y regalos? Estas son áreas en las que, de acuerdo con la dicotomía tradicional entre mercado y relaciones personales, o bien el dinero no debió siquiera haber penetrado, o la racionalización debió haber forzado cambios mayores, homogeneizando relaciones personales y sociales básicas y mercantilizando sentimientos vinculados a la familia, la amistad, la caridad o la muerte. Mi investigación muestra por el contrario que es realmente difícil suprimir el poder creativo de relaciones sociales supuestamente vulnerables. 


\section{¿A dónde va la sociología económica?}

No todos los observadores, por cierto, comparten mi entusiasmo por las tendencias actuales en sociología económica. Pasando revista a importantes compilaciones de trabajos dentro de este campo, Eric Cheney y Rob Faulkner (2003) y Jesper Sørensen (2003) han ofrecido críticas opuestas: Faulkner y Cheney declaran que los sociólogos económicos han excluido campos de análisis importantes como el delito y el "lado oscuro" del capitalismo que sociólogos anteriores habían analizado con bastante eficacia, mientras que Sørensen argumenta que los organizadores del campo han sido demasiado inclusivos al punto de arriesgarse a diluir el contenido intelectual de la disciplina.

Ambos están en lo cierto. En su celo por analizar correctamente los procesos institucionales, los sociólogos económicos han dedicado poca energía a cuestionar la existencia misma de las instituciones bajo estudio. Y la expansión temática que he estado celebrando ha reducido la coherencia teórica del campo, comparada con la que tenía cuando funcionaba básicamente como complemento de la teoría económica dominante. Sin embargo estamos en condiciones de pensar que surgirán nuevas y más críticas versiones de la sociología económica, y que nuevas síntesis están en camino.

En mi región del campo, en todo caso, veo a los estudiosos de los procesos económicos tomando tres pasos importantes y promisorios, aunque en parte contradictorios.

El primer paso, como sugerí antes, consiste en abandonar el argumento de las esferas separadas y los mundos hostiles en favor de análisis que persigan lazos sociales diferenciados con sus respectivos sistemas de contabilidad, medios, transacciones económicas, significados y delimitaciones particulares.

El segundo paso supone cuestionar la versión atenuada ya mencionada, según la cual todas las esferas involucran actividades económicas pero algunas son más afines al mercado -más racionales, más gobernadas por la eficiencia impersonal que otras, una condición que los analistas de las organizaciones frecuentemente describen como arms length, en la que las partes de la transacción son completamente independientes entre sí.

Un muy interesante tercer paso contradice parcialmente los anteriores. Tal como fue formulado por Michel Callon (1998) y Donald 
MacKenzie y Yuval Millo (2003), encontramos la idea de que la ciencia económica ha crecido alrededor de corporaciones y mercados, pero que a través de su mismo desarrollo ha reconfigurado esas corporaciones y mercados a su propia imagen. Si las teorías económicas realmente moldean relaciones y prácticas de ese modo, algunas áreas de la vida social podrían, después de todo, volverse más "mercantiles" que otras, a través de la performatividad de las teorías aplicadas a esas áreas.

Si es así, podría concebirse una nueva versión del segundo paso: si los constructivistas están en lo cierto, podría ser que algunas áreas construidas por la teoría económica se presten a una explicación superior por parte de la teoría económica comparadas con otras áreas como los hogares. En ese caso, los sociólogos económicos deberían pensar seriamente en formular teorías que puedan simultáneamente configurar y explicar otras arenas de producción, consumo, distribución y transferencia de valores que los queridos mercados y firmas de la vieja sociología económica.

No estoy sosteniendo que la performatividad provea el futuro de la sociología económica. Estoy afirmando, por el contrario, que la presencia de tan intrigantes ideas en un campo alguna vez estrechamente ligado a la ciencia económica hegemónica convierte a la sociología económica en una empresa académica vital, e incluso visionaria. 


\section{Bibliografía}

Aglietta, M. \& Orléan, A. (2002). La Monnaie: Entre Violence et Confiance. Paris: Odile Jacob.

Akin, D., \& Robbins, J. (Eds.).(1999). Money and Modernity: State And LocalCurrencies In Melanesia. Pittsburgh, Pa.:University of Pittsburgh Press.

L'argent en famille. (2005).Terrains 45 (September). Paris: Maison des Sciences de l'Homme.

Baker, B. (1987). What is money? A social structural interpretation. En M.S. Mizruchi \& M. Schwartz (Eds). Intercorporate Relations (pp. 109144). Cambridge: Cambridge University Press.

Blanc, J. (2000). Les Monnaies Parallèles. Paris: L'Harmattan.

Bloch, M. (1994). Les usages de l'argent. En M. Bloch (Ed.) Les Usages de l' Argent, Terrain, 23, pp. 5-10

Boltanski, L.,\& Chiapello, E. (1999). Le nouvel esprit du capitalisme. Paris: Gallimard. [Boltanski, L., \& Chiapello, E. (2002). El nuevo espi'ritu del capitalismo. Cuestiones de antagonismo, 13. Tres Cantos, Madrid: Akal Ediciones.]

Bourdieu, P. (2001). Las Estructuras Sociales de la Economía. Buenos Aires: Manantial.

Bourdieu, J., \& Heilbron, J. (2005). Préface à l'édition française. En Viviana A. Zelizer, La Signification sociale de l'argent (pp. 11-19). Paris: Seuil, collection Liber.

Caillé, A. (1994). Don, intérêt et désintéressement. Paris: La Découverte.

Callon, M. (1998). The Embeddedness of Economic Markets in Economics. En M. Callon (Ed.), The Laws of the Markets (pp. 1-57). Oxford: Blackwell.
Carruthers, B. G. \& W. Espeland. (1998). Money, Meaning and Morality. American Behavioral Scientist, 41, 1384-1408.

Carruthers, B. G. (2005). The Sociology of Money and Credit. En N. Smelser \& R. Swedberg (Eds.) The Handbook of Economic Sociology, second edition (pp. 355-378). New York: Russell Sage Foundation and Princeton: Princeton University Press.

Cohen, B. J. (2003). The Future of Money. Princeton, N.J.: Princeton University Press.

Collins, R. (1979). Review of The Bankers, by Martin Meyer. American Journal of Sociology, 85: 190-194.

Convert, B. \&, Heilbron, J. (2004). Genèse de la sociologie économique américaine. En Johan Heilbron, J., Lenoir, R. \& Sapiro, G. (Eds), Pour une histoire des sciences sociales. Hommage à Pierre Bourdieu (pp. 223241). Paris : Fayard.

Cusin, F, \& Benamouzing, D. (2004). Économie et sociologie. Paris: Quadrige/PUF.

De La Pradelle, M. (1996). Les vendredis de Carpentras. Paris: Fayard.

Dodd, N. (1994). The Sociology of Money. New York: Continuum.

Dodd, N. (2005). Reinventing Monies in Europe. Economy and Society, 34, $558-83$.

Faulkner, R. R., \& Cheney, E. (2003). Review of The New Economic Sociology: Developments in an Emerging Field, by Guillén, M. F., Collins, R., England, P. \& Meyer, M. (Eds). Contemporary Sociology, 32, 445-447.

Fine, B., \& Lapavitsas, C. (2000). Markets and money in social theory: what role for economics? Economy and Society, 29, 357-382.
Fishman, R. M., \& Messina, A. M. (Eds.) (2006). The Year of the Euro: The Cultural, Social, and Political Import of Europe's Common Currency. Chicago: University of Notre Dame Press.

Gilbert, E. (2005). Common cents: situating money in time and place. Economy and Society, 34, 357-388.

Gislain, J.-J., \& Steiner, P. (1995). La sociologie économique 1890-1920. Paris: Presses Universitaires de France.

Guérin, I. (2003). Femmes et économie solidaire. Paris: La Découverte.

Guyer, J. I. (Ed.). 1995 Money Matters. Portsmouth, NH: Heinemann.

Habermas, J. (1989). The Theory of Communicative Action Volume 2. Boston: Beacon Press. [Habermas, J. (1990). Teori'a de la accio'n comunicativa. Buenos Aires: Taurus.]

Hassoun, J.-P. (Ed.). (2005). Special Issue, Négoces Dans La Ville. Ethnologie francaise, 35.

Helleiner, E. (2003). The Making of National Money: Territorial Currencies in Historical Perspective. Ithaca: Cornell University Press.

Ingham, G. (2001). Fundamentals of a Theory of Money: Untangling Fine, Lapavitsas and Zelizer. Economy and Society, 30, 304-323.

Ingham, G. (2004). The Nature of Money. Cambridge, U.K.: Polity.

Keister, L. (2002). Financial Markets, Money, and Banking. Annual Review of Sociology, 28, 39-61.

Lapavitsas, C. (2005). The Social Relations of Money as Universal Equivalent: a response to Ingham. Economy and Society, 34, 389-403.

Leyshon, A., \& Thrift, N. (1997). Money Space: Geographies of Monetary Transformation. London: Routledge. 
MacKenzie, D., \& Millo, Y.. (2003). "Constructing a Market, Performing Theory: The Historical Sociology of a Financial Derivatives Exchange." American Journal of Sociology 109: 107-145.

Mizruchi, M.S.,\& Brewster Stearns, L. (1994). Money, Banking, and Financial Markets. En N. Smelser \& R. Swedberg (Eds.). The Handbook of Economic Sociology (pp. 313-341). Princeton, N.J.: Princeton University Press and New York: Russell Sage Foundation.

Pahl, J. (1989). Money and Marriage. London: Palgrave Macmillan.

Parsons, T. (1967). On the Concept of Influence. Sociological Theory and Modern Society. New York: Free Press.

Parry, J., \& Bloch, M. (Eds). (1989). Money \& The Morality of Exchange. New York: Cambridge University Press.

Raineau, L. (2004). L'utopie de la monnaie immatérielle. Paris: Puf.

Saint-Jean, I.T., \& Steiner, P. H., (Eds). (2005) Sociologies Économiques. L'Année sociologique, 55.

Sciardet, H. (2003). Les marchands de l'aube. Ethnographie et théorie du commerce aux Puces de Saint-Ouen. Paris: Economica.

Servet, J-M. (Ed.). (1999). Une Économie Sans Argent: Les Systèmes

d'Echange Local. Paris: Éditions Du Seuil.

Servet, J.-M. \& Guérin, I. (Eds). (2002). Exclusion et Liens Financiers. Paris: Economica.

Singh, S. (1995). Marriage Money: The social shaping of money in marriage \& banking. St. Leonards, Australia: Allen \& Unwin.
Smelser, N., \& Swedberg, R. (Eds.). (2005). Handbook of Economic Sociology, second edition. Princeton, N.J.: Princeton University Press and New York: Russell Sage Foundation.

Sørensen, J. B. (2003). Review of The New Economic Sociology: Developments in an Emerging Field, by M. F. Guillén, R. Collins, P. England, \& M. Meyer, editors. Administrative Science Quarterly, 48, 534-537

Steiner, P. (1999). La sociologie économique. Paris: La Découverte. (2003). "Gift of Blood and Organs: The Market and "Fictitious" Commodities." Revue francaise de sociologie, 44 Supplement: 147-162.

Wacquant, L. (2002). Corps et âme. Paris: Agone. [Wacquant, L. (2006) Entre las cuerdas. Cuadernos De Un Aprendiz De Boxeador. (2006). Buenos Aires: Siglo XXI.]

Weber, F., S. Gojard, \& A. Gramain. (2003). Charges de Famille. Paris: La Découverte.

Weber, F. (2005). Le sang, le nom, le quotidian: une sociologie de la parenté pratique. Paris: Aux lieu d"être.

Woodruff, D. (1999). Money Unmade: Barter and the Fate of Russian Capitalism. Ithaca, N.Y.: Cornell University Press.

Zelizer, V. (1994). The Social Meaning of Money. New York: Basic Books.

Zelizer, V. (2005a). Missing Monies: Comment on Nigel Dodd, "Reinventing Monies in Europe." Economy and Society. 34, 585-588.

Zelizer, V. (2005b). The Purchase of Intimacy. Princeton: Princeton University Press. 